Revista de la red interuniversitaria de estudios sobre las literaturas rioplatenses contemporáneas en Francia

$14 \mid 2016$

Levrero

\title{
Una novela oscura : Desplazamientos
}

\section{Ezequiel De Rosso}

URL: http://journals.openedition.org/lirico/2260

DOI: $10.4000 /$ lirico.2260

ISSN: 2262-8339

Editor

Réseau interuniversitaire d'étude des littératures contemporaines du Río de la Plata

Referencia electrónica

Ezequiel De Rosso, «Una novela oscura : Desplazamientos », Cuadernos LIRICO [En línea], 14 | 2016,

Puesto en línea el 07 junio 2016, consultado el 06 mayo 2019. URL : http://journals.openedition.org/ lirico/2260 ; DOl : 10.4000/lirico.2260

Este documento fue generado automáticamente el 6 mayo 2019.

\section{(c) (i) (9)}

Cuadernos LIRICO está distribuido bajo una Licencia Creative Commons Atribución-NoComercialSinDerivar 4.0 Internacional. 


\title{
Una novela oscura : Desplazamientos
}

\author{
Ezequiel De Rosso
}

1.

En agosto de 1964, Julio Cortázar respondía una carta en la que Roberto Fernández Retamar expresaba su admiración por Rayuela :

Mira, desde luego que lo que hayas podido encontrar de bueno en el libro me hace muy feliz; pero creo que en el fondo lo que más me ha estremecido es esa maravillosa frase, esa pregunta que resume tantas frustraciones y tantas esperanzas : "¿De modo que se puede escribir así por uno de nosotros ?" Créeme, no tiene ninguna importancia que haya sido yo el que escribiera así, quizá por primera vez. Lo único que importa es que estemos llegando a un tiempo americano en el que se pueda empezar a escribir así (o de otro modo, pero así, es decir con todo lo que tú connotas al subrayar la palabra). ${ }^{1}$

2 En 1996 Mario Levrero, que había ya publicado "Diario de un canalla" y El discurso vacío, escribe en una de sus "Irrupciones" : " Encontré en el procesador de textos un botón que, al oprimirlo, permite ir tachando todo to que se escribe. Lo interesante de este procedimiento es que permite ir tachando al mismo tiempo que se escribe. Me siento tentado de seguir escribiendo así, siempre. ${ }^{2}{ }^{2}$

El escenario que presenta la primera cita (el escenario en el que Levrero escribe y publica sus primeros textos) es el escenario dominado por el despliegue técnico de Rayuela, por la intensidad con la que se subraya la palabra (presumiblemente caligráfica). En treinta años, Levrero se ha hecho un escritor de culto (y por eso puede escribir una columna en Posdata) y en el centro de sus preocupaciones está la técnica, pero en un sentido muy distinto al de Fernández Retamar y Cortázar. Treinta años después, la técnica de escritura es, literalmente, los dispositivos por los cuales se pone en marcha la materia, la letra. «Escribiendo, así, siempre» no se relaciona con una voluntad o, mejor aún, una expresión, sino que se relaciona con el descubrimiento de una técnica: es escribir con estos instrumentos, con estas máquinas, « escribir así » ya no se subraya caligráficamente, sino que se tacha tipográficamente. 
4 En esa diferencia, se trama la distancia entre dos modos, dos impulsos, de la escritura. Hay en esa distancia una contradicción del optimismo indudable del texto de Cortázar : la expresividad es reemplazada por la ironía y el azar. Más aún : no sólo la utopía del texto es escribir y tachar a la vez, no sólo ese procedimiento no "connota" (es un juego con las formas de la representación), no sólo es una escritura producto de la curiosidad antes que el resultado de un momento histórico, sino que se nos presenta como la formulación extrema de un programa que abarca zonas significativas de la escritura levreriana.

5 Ese programa alcanza su formulación más densa en una novela publicada algunos años antes, Desplazamientos.

\section{Módulos}

6 Escrita entre 1982 y 1984, y publicada originalmente en 1987, Desplazamientos debe pensarse en una constelación de textos cuyos ejemplos extremos pueden ser Caza de conejos (1973) y Ya que estamos (1980), pero en la que también podría incluirse "Precaución" (1980), "Sistema" (1984) o "La nutria es un animal del crepúsculo (collage)" ("actualizado" en 1984). ${ }^{3}$ Nos referimos a un conjunto de textos compuestos por breves fragmentos cuya relación viene tramada menos por la peripecia que por la variación, inversión y repetición de las piezas que los componen. En este sentido, la escritura de Levrero entre 1973 y 1984 se nos presenta como un intento de despojar a la literatura de toda clausura (narrativa o mimética) y exhibirla como arte combinatoria. ${ }^{4}$. El último texto en el que predomina esta configuración, "Sistema", hace explícita esa disposición escrituraria :

Descubro que no tengo ganas de seguir desarrollando esta narración, aunque existen infinidad de variantes posibles, algunas muy atractivas; en verdad podría continuarse indefinidamente. Pero en este no tener ganas hay algo más que una abulia ; hay, tal vez, algo de temor (esto, que estoy escribiendo - por ejemplo-, puede ser una caja más; puede haber una caja más grande que lo contenga y lo delate como ficticio, y puedo yo mismo estar encerrado en esa caja, en esa ficción ; entonces, ¿qué soy?, ¿qué es el lector ? Etcétera). ${ }^{5}$

7 El fragmento explicita los límites de esa constelación "experimental” ( de variantes posibles » que podrían « continuarse indefinidamente ») y puede leerse como la despedida de esos juegos de niveles y versiones : ante la duda que impide distinguir la ficción de la experiencia, habrá que, no sin cierta fe en los sentidos, abandonar la ficción. Así, el texto que sigue, en El portero y el otro, a esta declaración (¿de principios?) es "Apuntes bonaerenses" (escrito en 1988), que ya debe pensarse en la constelación autobiográfica. ${ }^{6}$

8 En este sentido, Desplazamientos probablemente deba leerse como el texto más denso de toda la serie. Tal vez por eso, en una primera lectura la novela produce un efecto de desconcierto : la trama, de una extrema simplicidad (un hombre va a cobrar el alquiler a una casa de pensión que heredó de su padre), parece recomenzar una y otra vez. Se trata de variaciones que resultan en algunos casos mínimas : un diálogo que, sin solución de continuidad sucede dos veces, variando solamente la puntuación ${ }^{7}$; en otros casos se trata de episodios que tienen diversas conclusiones (por ejemplo, las reacciones del narrador frente a una escena de lesbianismo redundan en una violación ${ }^{8}$, en un acto vouyerismo ${ }^{9} \mathrm{o}$ en una contemplación mística en la que el sexo del narrador " se mantenía curiosamente ajeno a la escena $»)^{10} \mathrm{y}$ aún en líneas narrativas completamente obliteradas por una 
abrupta vuelta a líneas anteriores (como el seguimiento de una mujer desconocida por la ciudad). ${ }^{11}$ La textualidad de Desplazamientos se da a leer como un ejercicio de narrativa arborescente, como la actualización de un conjunto de posibilidades para el relato. ${ }^{12}$

En este sentido Desplazamientos pertenece a una tradición persistente, aunque no siempre evidente en la narrativa latinoamericana. En efecto, al menos desde las vanguardias, han existido escritores que se han valido de lo que, a falta de mejor nombre, podríamos llamar "escritura modular": una escritura fragmentaria, que tiende a dislocar la secuencia narrativa en foco y tiempo y que tiende a una construcción adjuntiva del sintagma narrativo, antes que a la construcción de secuencias temporales y causales. Esa escritura, por lo tanto, enfatiza el efecto de artificio antes que el de "verosimilitud", tiende a mostrar las costuras del tejido narrativo antes que a suturarlas.

10 Una breve historia de la escritura modular debería empezar por las novelas vanguardistas de Arqueles Vela (como "La señorita etc." - 1922) y continuar con "novelas" como El señor Presidente (1946, pero concluida en 1933), y Morirás lejos, de José Emilio Pacheco (1967). Hacia los sesenta, después de Pedro Páramo (1955), esa lógica puede formalizarse. En este sentido, Rayuela (1963) de Cortázar es el límite de un modo de comprender ese tipo de articulación y 62. Modelo para armar (1968) el comienzo de un nuevo modo. Porque, por una parte, ambos textos declaran la lógica que los rige y pueden, por lo tanto, plantear opciones de recorrido (y por eso incluyen, ambas, "programas de lectura"). Y por otra parte porque en ambas, pero sobre todo en la segunda, esos fragmentos que en los textos previos (digamos, de Arqueles Vela a José Emilio Pacheco) se nos presentaban como la denuncia de las convenciones realistas, como la demostración de la potencia del paradigma sobre el sintagma, ahora se nos muestran, antes que como la puesta en cuestión de la narración, como la posibilidad de construir otro tipo de narración, un relato en red, un relato de lógica espacial en el que la simultaneidad de los hechos no se vea adelgazada por la linealidad del relato. En este sentido, la escritura modular que va de 62. Modelo para armar a, digamos, Los detectives salvajes (1998) de Roberto Bolaño, intenta reconducir un procedimiento vanguardista a una estrategia rupturista en la prosa narrativa. ${ }^{13}$

11 Los "módulos" con los que se arma Desplazamientos, en cambio, remiten a una sola línea narrativa y un solo foco, es decir que no expanden el universo representado, sino que señalan que los episodios podrían haber sido escritos de otro modo. Los módulos se presentan, pues, como variaciones. Esa dimensión parece central para pensar el horizonte en el que se recorta Desplazamientos. Porque si hasta los sesenta la escritura en módulos tiende a ser un cuestionamiento de la mímesis (como prueban tanto los textos de Vela como los de Macedonio Fernández) y, a partir de Rulfo y Cortázar, una ampliación de la mímesis ; en Desplazamientos se nos presentan como explícita variación escrituraria. Dicho de otro modo : no se trata sólo de mostrar que otros episodios desarticulados causalmente (Vela) son posibles o que la escritura tiene primacía sobre la representación (Fernández), sino que se trata de mostrar que escribir es decidir sobre un conjunto de posibilidades casi siempre descartadas por la puesta en discurso. ${ }^{14}$ Esa atención a la lógica propia de la escritura, a la lógica del deshecho, distingue a Desplazamientos de usos previos de la escritura modular. 


\section{Variaciones}

12 La lógica de la variación escrituraria también distingue a Desplazamientos entre los textos contemporáneos a su publicación. En efecto, bien podría decirse que si la década de los setenta, posterior a la emergencia de "la nueva narrativa latinoamericana", es la década en la que se reivindicaron los diversos realismos (como muestran los textos de Antonio Skármeta, Andrés Caicedo o la Onda) y las formas del testimonio, entonces puede pensarse que durante la década de los ochenta gana la escena la dificultad de representación de lo real. En efecto, diversos observadores han señalado que durante la década aparece un conjunto de textos que elaboran la incertidumbre de lo real o bien que difuminan las fronteras entre texto y real. ${ }^{15}$ Dos casos pueden servirnos a definir este panorama.

13 Un escritor recurrentemente asociado a este tipo de especulación, Juan José Saer, publica en 1984 Glosa, que señala desde su título la relación difícil entre discurso y real. Como se recordará, la novela narra cómo Ángel Leto y El Matemático reconstruyen, a lo largo de un recorrido de algo más de veinte cuadras, una fiesta a la que no asistieron. La atención, la ironía de Saer con respecto al detalle y a las versiones e incluso a la escena del relato subrayan en qué medida cualquier relato sobre lo real es siempre una hipótesis, incluso si se lo ha captado a partir de una "experiencia".

14 En 1984 también se publica Arturo, la estrella más brillante, de Reinaldo Arenas. En la breve novela se cuentan los infortunios de un amigo de Arenas que fue recluido en un centro de reeducación para homosexuales en Cuba. El texto, escrito en un solo párrafo, concluye con las fantasías de elevación al cielo de Arturo volviéndose realidad. Se trata, pues, del pliegue de una versión de los hechos (la fantasía de Arturo) sobre los hechos mismos : la negación, si se quiere, de la posibilidad (de la necesidad) de conocer los hechos por la vía del relato.

15 La compresión extrema, en espacio y tiempo, tanto del texto de Arenas como del texto de Saer, sugieren que es la concentración, la miniaturización lo que permite ese acceso privilegiado a lo real. También en Desplazamientos ese despliegue sucede en un tiempo acotado (una noche y el día subsiguiente), a partir de un procedimiento riguroso (el despliegue de las variaciones), y un espacio severamente limitado (la casa). ${ }^{16} \mathrm{Si}$ en los textos de Saer o Arenas las versiones son la muestra de la imposibilidad de representar; si, de hecho, se pliegan tanto sobre lo real (el caso de Arenas) como entre sí (el caso de Saer), el texto de Levrero es el despliegue arborescente de esas versiones. Un texto analítico, ahí donde la literatura de los contemporáneos construye una literatura sintética. ${ }^{17}$

16 Esa dimensión analítica redunda en un efecto "modular" considerablemente más evidente que lo que puede verse en la obra de Saer y Arenas: en Desplazamientos abundan los blancos y las repeticiones que señalan el fin o el comienzo de una nueva variación. Esta evidencia, lleva incluso a la clausura del relato : el final del último capítulo no es más que el reenvío entre fragmentos previamente leídos. Así, el final de Desplazamientos no es más que el "cortocircuito" del procedimiento, como si ese hubiera sido el objeto privilegiado del texto. De ahí que en el final Nadia y su mundo desaparezcan " porque yo he dejado de inventarlos » ${ }^{18}$ : la operación ha sido evidenciada, las variaciones exhiben la figura de quien escribe y el texto concluye. 
17 Si se piensa que esa "invención" que menciona el final aparece relacionada con el problema de lo que se desecha en la construcción de un relato, podemos hipotetizar que Desplazamientos es la primera novela en la que se concreta ese proyecto al que Levrero volvería en su etapa autobiográfica (sobre todo, claro, en El discurso vacío, un largo excurso sobre cómo borrar y escribir). Si se quiere, una novela hecha de borradores, falsos comienzos y non-sequiturs. Desplazamientos es una de las formas de «escribir así siempre ", una novela escrita con lo que debería estar tachado.

18 Pero también en este sentido puede verse cómo el problema de lo real gana la escena. Porque la distribución de las variaciones en Desplazamientos no es continua ni constante. Algunos episodios (notablemente el primer encuentro con Nadia) requieren de varias versiones y otros son contados una sola vez, hay fragmentos de prosa fluida (todas las escenas en las calles) y otros notablemente barrocos (todas las escenas en los pasillos). Todo sucede, en fin, como si se accediera a las diversas intensidades de la escritura, como si Desplazamientos pudiera leerse como el trabajo de escribir antes que como la representación de una peripecia. Se toca aquí lo real de la escritura, su trabajo : como si el texto fuera la exhibición de una experiencia, y de ahí derivara su condición fragmentaria y arborescente, arbitraria, sujeta al deseo y al tiempo de la mano que escribe. ${ }^{19}$

\section{Novelas}

19 Desplazamientos debe su título, sin embargo, no sólo a los modos en los que la trama se reescribe en múltiples fragmentos, sino al movimiento recurrente (incluso si no se trata de variaciones) del narrador por la casa que heredó de su padre. Y las casas siniestras son una figura que caracteriza cierta zona de los relatos de Levrero (El lugar [1969], "La casa abandonada", "Los muertos", “Todo el tiempo"): son laberintos, lugares en los que la lógica del mundo exterior tiende a la disolución. ${ }^{20}$ La casa de Desplazamientos, por ejemplo, tiene pasillos tortuosos que terminan en virtuales mazmorras ${ }^{21}$, en la casa el encierro amenaza constantemente ${ }^{22}$, las proporciones son engañosas ${ }^{23}$ y tiene entre sus inquilinos a una bruja. Finalmente, la casa es el umbral que permite acceder a otro tipo de realidad : « [la casa] me atrajo para fascinarme y para meterme en eso que esa noche había comenzado a meterme y que todavía no llegaba a percibir claramente en qué consistía ni en qué podría terminar. $»^{24}$.

20 Esa fascinación depende, como señala inmediatamente el narrador, de dos factores : « si [la casa] me atrajo [...] había hecho falta, en primer lugar, Nadia, y luego, que ésta hubiera sido mi casa, cuando niño. $»^{25}$ En efecto, la casa, a diferencia de otras casas levrerianas, es una herencia. Esa herencia parece poseer al narrador a través de la casa : la casa está llena de sombras y esa oscuridad remite una y otra vez al poder que el padre parece tener sobre el narrador. Por una parte, las sombras convocan siempre sentidos asociados lo siniestro : en las sombras se « conspira ${ }^{26}$, las sombras de una vela « despiertan » al narrador ${ }^{27}$, las sombras estimulan los violentos encuentros sexuales con Nadia. ${ }^{28}$ Por otra, las sombras resultan una figuración del padre : la sombra del narrador es la sombra de su padre ${ }^{29}, y$ domina sus acciones (« Sabía, además, que toda mi actuación estaba como controlada por la sombra de mi padre. $»^{30}$; el deseo sexual del narrador aparece guiado por la sombra de su padre).$^{31}$ En este sentido, Desplazamientos puede leerse como una historia de posesión.

21 Por otra parte, la atracción de Nadia es eminentemente sexual y, de hecho, los episodios que mayor cantidad de resoluciones tienen en la novela se relacionan con su sexualidad y 
el modo en que el narrador se relaciona con ella. Esa relación es, como señala el propio narrador, tortuosa y perversa. En este sentido, en varios de los módulos el narrador aparece sexualmente fascinado por la leche que mana de los pechos de Nadia: en dos módulos bebe de ellos ${ }^{32}$, en otro aparece relacionada con el sexo como experiencia santa. ${ }^{33}$ Esa "infantilización" del narrador recorre el texto y es parte del poder de la casa: rememorando el primer encuentro con Nadia el narrador reflexiona que se trata « una casa que en mi memoria tenía el tamaño y la importancia de un templo arquetípico ; la casa ha revivido al niño que me habitaba y ahora este niño se siente desconcertado, culpable y temeroso $»{ }^{34}$ Hay, pues, una relación no poco frecuente en los textos de Levrero, entre sexo y sacralidad.

22 Como puede verse, en verdad los tres elementos (la casa, el sexo infantilizado, el padre) aparecen directamente relacionados. Quedar atrapado en esa red no es, sin embargo, necesariamente dañino. Cuando el narrador sale de la casa, la perspectiva se aclara de una manera ambigua :

Al llegar cerca de un farol [...] las cosas se hacen más tangibles y menos interesantes, y al quedar atrás la luz vuelven poco a poco a integrarse al misterio. Se me ocurre que la verdad profunda de las cosas es necesariamente difusa, imprecisa, inexacta ; que el espíritu se alimenta del misterio y huye y se disuelve cuando lo que llamamos precisión o realidad intenta fijar las cosas en forma determinada $-o$ en un concepto. ${ }^{35}$

Conforme avanza el texto (aunque no necesariamente el relato) el narrador logra tomar distancia de los episodios y finalmente los recuerda con « una cierta frialdad $»^{36}:$ «Y a medida que las emociones se iban asentando y reubicando alrededor de esas imágenes o entrelazadas con ellas, se iba definiendo poco a poco y cada vez con mayor precisión, un esquema bastante claro y sencillo de lo que, en adelante, debía hacerse con respecto a la casa y sus habitantes ${ }^{3} .^{37}$

24 La tangibilidad de las cosas las hace menos interesantes, y a la vez, esa inexactitud, esa oscuridad que las envuelve parece necesaria para finalmente deshacerse de la angustia y la violencia que definen al narrador. Ese es, claro, uno de los sentidos posibles para el epígrafe de Jung que abre la novela. ${ }^{38}$ Es posible, sin embargo, pensar ese epígrafe en una línea completamente diferente: lo que comienza con Jung no es una novela junguiana, sino una novela de terror.

25 En efecto, es posible argumentar que los motivos que hemos someramente resumido, parecen referir al relato gótico antes que al caso psicoanalítico. La casa embrujada, la sexualidad infantilizada, la sombra del padre, la posesión por fuerzas oscuras son algunos de los tópicos que definen al género. ${ }^{39}$ Así es que podríamos pensar que así como en la novela que acompaña a Desplazamientos, "Fauna", la parapsicología toma la forma del relato policial (y el epígrafe y la dedicatoria anuncian este desvío), Desplazamientos cuenta una "tesis psicoanalítica" con las figuras de un relato de terror. ${ }^{40}$

En Desplazamientos las tesis de Jung pueden eventualmente servir para explicar un personaje o un conflicto, pero sobre todo es un dispositivo que permite un desarrollo narrativo, una trama, antes que su explicación. Esa levedad, esa concepción lúdica del texto literario, es una marca del estilo de Mario Levrero y explica en parte su marginación para una crítica como la producida durante los años ochenta, acosada por la resistencia de lo real. ${ }^{41}$ 


\section{5.}

27 Se ha dicho, la obra de Levrero tiende a la "superficialidad", a la construcción de personajes y peripecias que parecen existir en virtud de la escritura y sólo para satisfacer su desarrollo. En este sentido, los personajes parecen llevados por los hechos antes que ser agentes de la peripecia. ${ }^{42}$ En este punto, Desplazamientos es una novela típicamente levreriana. Menos se ha señalado otra estructura recurrente en los libros de Levrero : el relato toma forma cuando hay una misión, una tarea que cumplir y, a la vez, cuando esta no puede cumplirse. En efecto, desde Gelatina (1968) hasta "Los carros de fuego" (2003) la acción es el producto la forma de un desvío, un error o una confusión. Lo que se cuenta es, pues, lo que sucede mientras no se subsana el error o no se retoma el "camino principal".

28 La importancia de Desplazamientos en la obra de Levrero radica en la transformación del desvío en el centro productivo del texto. Verdadero fractal, Desplazamientos encuentra en todos los niveles la forma del desvío: en la trama (tratar de cobrar un alquiler y no terminar nunca de cobrarlo), en la estructura (construir un relato con todos los desvíos del relato), en la escritura (hacer de los posibles de la escritura un uso desviado; tornar escritura lo que no es más que un "borrador"), en el horizonte referencial (usando el psicoanálisis para construir un relato gótico). ${ }^{43}$ Desvío, finalmente, de lo que tal vez el propio Levrero hubiera querido escribir.

29 Tal vez por eso, porque es la novela que hace posible " escribir así, siempre », la que transforma un procedimiento narrativo característico de su estilo en una matriz de escritura para todos los niveles, Desplazamientos siempre fue mencionada por Levrero como su novela favorita. ${ }^{44}$ En una entrevista de 1987, el escritor dice que está escribiendo una novela « cuyo título provisorio es Novela luminosa, en contraposición con la 'novela oscura' que finalmente tomó el nombre de Desplazamientos $»{ }^{45}$ Es posible pensar entonces que a partir de Desplazamientos comienza la búsqueda de nuevos modos de escritura, una escritura probablemente imposible, una utopía de la que diversos textos dan testimonio en su éxito y su fracaso.

Tal vez por eso, en La novela luminosa se lee :

Esa novela oscura existe, aunque inacabada y tal vez inacabable. Estoy como prisionero de ella, de su atmósfera, de las oscuras imágenes y los más oscuros sentimientos que hace ya un par de años me impulsaron a escribirla. Casi diariamente despierto (...) con la imperiosa necesidad de destruirla. (...) Ahora debo escribir (la novela oscura) y deseo escribir (la novela luminosa). ${ }^{46}$

Desvío, entonces, del deseo, el propio Levrero parece objeto de Desplazamientos.

\section{NOTAS}

1. Julio Cortázar, “Carta a Roberto Fernández Retamar”, en Cartas. vol. 2. 1964-1968, ed. Aurora Bernárdez, Buenos Aires : Alfaguara, 2000, p. 742.

2. Mario Levrero, Irrupciones. Montevideo : Cactus editora, 2013, p. 43. 
3. Nos referimos aquí a las fechas de escritura, puntillosamente señaladas por Levrero en casi todos sus textos. "Precaución" y "Sistema" fueron incluidos en El portero y el otro (1992), "La nutria es un animal del crepúsculo (collage)", en Espacios libres (1987).

4. En Caza de conejos, por ejemplo, el último fragmento invierte todas las frases del primero; "Precaución" es un texto constituido en su totalidad por notas dentro de notas (hasta perder la referencia del primer texto); "La nutria es un animal del crepúsculo (collage)" es una adjunción de recortes de diferentes fuentes cuyo objeto privilegiado parece ser encontrar un ritmo y una textura.

5. Mario Levrero, “Sistema”, en El portero y el otro, Montevideo : Arca, 1992, p. 115.

6. En otro lugar hemos señalado que casi todos los textos de Levrero pueden organizarse en constelaciones. Todavía existirán algunos textos (Dejen todo en mis manos, El alma de Gardel, "Los carros de fuego") que no terminan de ingresar en la escritura autobiográfica que caracteriza la última etapa de su producción. Estos textos (escritos entre 1993 y 2003) ya muestran, sin embargo, un viraje creciente hacia la autobiografía. Ver Ezequiel De Rosso. "Otra trilogía : las novelas policiales de Mario Levrero.”. La máquina de pensar en Mario. Ensayos sobre la obra de Levrero . Ezequiel De Rosso (sel. y pról.). Buenos Aires : Eterna Cadencia, 2013. Pp. 141-163.

7. Mario Levrero, Fauna / Desplazamientos. Buenos Aires : Mondadori, 2012, pp. 149-150.

8. Mario Levrero, Fauna / Desplazamientos,.ibid, p. 221.

9. Mario Levrero, Fauna / Desplazamientos,.ibid, p. 228.

10. Mario Levrero, Fauna / Desplazamientos,.ibid, p. 231.

11. Mario Levrero, Fauna / Desplazamientos,.ibid, pp. 184-192.

12. Desplazamientos puede leerse como la contrapartida libresca de la sección "Novela en construcción", que Levrero dirigió en Humor \& Juegos entre abril y noviembre de 1981. Se trataba de un concurso en el que, a partir de un capítulo inicial los lectores debían enviar una continuación. La redacción elegía los dos capítulos que mejor se ajustaba a lo ya escrito, produciendo una bifurcación que seguiría en las siguientes entregas. En este movimiento, Levrero era menos un escritor que un "operador", un montajista de fragmentos, como, si se quiere, parece presentarse al lector en Desplazamientos.

13. Para una elaboración de la diferencia entre vanguardia y ruptura, ver Umberto Eco, "El grupo 63, el experimentalismo, la vanguardia", en De los espejos y otros ensayos. Buenos Aires : Lumen, 1988, pp. 99-111.

14. En conversación con Cristina Siscar, señala Levrero: "O sea que uno va leyendo y en determinado momento se repite un fragmento que toma por otro camino que se trunca o se continúa más adelante. Es una obra ramificada. Ahora me siento satisfecho." Ver Cristina Siscar : "Las realidades ocultas". En Mario Levrero. Un silencio menos. Elvio Gandolfo (comp.). Buenos Aires : Mansalva, 2013. Pp. 46.

15. Escribe José Luis De Diego, comentando las posiciones teóricas de Sarlo, Piglia y Saer durante la década: "lo real es ahora [...] una dimensión que es menester explorar, problematizar y densificar, exponiendo su carácter enigmático e irreductible” (De Diego, José Luis. "1976-1989. Dictadura y democracia : crisis de la industria editorial". En José Luis de Diego (director). Editores y políticas editoriales en Argentina (1880-2010). Buenos Aires : FCE, 2014, p. 197). Para otro desarrollo sobre la relación entre lo real y lo literario durante la década de los ochenta en Argentina ver Florencia Garramuño. La experiencia opaca. Literatura y desencanto. Buenos Aires : FCE, 2009. Para el caso brasileño ver Garramuño (ibid.) y Raúl Antelo "La arealidad setentista". En Florencia Garramuño, Gonzalo Aguilar, Luciana Di Leone (comps.). Experiencia, cuerpo y subjetividades. Literatura brasileñas contemporánea. Buenos Aires : Beatriz Viterbo, 2007. Pp : 183-196.

16. Existen, sin embargo, zonas de fuga de estos recursos : así como no todos los fragmentos son objeto de variación, existe una coda (las últimas dos páginas) que sucede dos semanas después de la aventura nocturna y hacia el final (y en una de las variaciones del primer capítulo) se cuentan episodios que suceden fuera de la casa. Estas "excepciones" refuerzan el efecto de clausura, 
subrayan el poder de la casa (y de los procedimientos). En este sentido, no resulta sorprendente que, incluso cuando se ha escapado al poder ominoso de la casa, el texto vuelve a Nadia, a las variaciones, a la casa : son estas sus matrices constitutivas y, como veremos enseguida, el único modo de dar clausura al texto.

17. De hecho, pero eso no tenemos espacio para desarrollar aquí, toda la obra de Levrero puede pensarse, según el período como el espejo deformante, la versión empobrecida de los fenómenos que ganaban espacio en la literatura latinoamericana de cada momento histórico: el relato fantástico y el realismo mágico de los sesenta, el relato sobre lo real y sus versiones de los ochenta, el giro autobiográfico en los dos mil.

18. Mario Levrero, Fauna / Desplazamientos, op. cit., pp. 274.

19. Florencia Garramuño (op. cit., p. 23), refiriéndose a las escrituras de Argentina y Brasil durante los ochenta señala: "Tanto en narrativas como en poesías de la época, son varios los dispositivios que conspiran contra la idea de una obra contenida, regida por un principio de rigor formal. En su lugar, proponen una concepción de la escritura como puro devenir, que no sólo desarma la idea de obra, sino que a menudo se dirige incluso explícitamente a cuestionar la posibilidad de enmarcar o de contener dentro de una obra la pura intensidad que la escritura, en tanto que escritura de una experiencia, pretende registrar."

20. "La casa abandonada" fue publicado en La máquina de pensar en Gladys (1970), "Los muertos" en Espacios libres, “Todo el tiempo" en el libro homónimo (1982). Para una lectura exhaustiva del lugar de las casas en la narrativa de Levrero, ver Martín Kohan. "La idea misma de ciudad". En Ezequiel De Rosso (sel. y pról.). La máquina de pensar en Mario. Ensayos sobre la obra de Levrero. Buenos Aires : Eterna Cadencia, 2013. Pp. 113-126.

21. Mario Levrero, Fauna / Desplazamientos, op. cit., pp. 162-163 у 258.

22. Mario Levrero, Fauna / Desplazamientos, ibid., p. 167.

23. Mario Levrero, Fauna / Desplazamientos, ibid., pp. 177 y 259.

24. Mario Levrero, Fauna / Desplazamientos, ibid., p. 236.

25. Mario Levrero, Fauna / Desplazamientos, ibid., p. 236.

26. Mario Levrero, Fauna / Desplazamientos, ibid., p. 158.

27. Mario Levrero, Fauna / Desplazamientos, ibid., p. 159.

28. Mario Levrero, Fauna / Desplazamientos, ibid., pp. 148 y 181.

29. Mario Levrero, Fauna / Desplazamientos, ibid., pp. 144, 174, 182.

30. Mario Levrero, Fauna / Desplazamientos, ibid., p. 172.

31. Mario Levrero, Fauna / Desplazamientos, ibid., pp. 156 y 236.

32. Mario Levrero, Fauna / Desplazamientos, ibid., pp. 151 у 233.

33. Mario Levrero, Fauna / Desplazamientos, ibid., p. 231.

34. Mario Levrero, Fauna / Desplazamientos, ibid., p. 161.

35. Mario Levrero, Fauna / Desplazamientos, ibid., p. 186.

36. Mario Levrero, Fauna / Desplazamientos, ibid., p. 269.

37. Mario Levrero, Fauna / Desplazamientos, ibid., p. 270.

38. «A todo individuo le sigue una sombra (...) Si las tendencias reprimidas de la sombra no fueran más que malas, no habría problema alguno. Pero, de ordinario, la sombra es tan sólo mezquina, inadecuada y molesta, y no absolutamente mala » (Carl Gustav Jung) (Mario Levrero, Fauna / Desplazamientos, ibid., p. 139).

39. Para un análisis de estos motivos, ver María Negroni "El castillo lírico", en La noche tiene mil ojos. Buenos Aires : Caja negra, 2015, pp. 19-21 y Angel Faretta, "Notas para una introducción al cine de horror", en Espíritu de simetría. Buenos Aires : Djaen, 2007, pp. 513-517.

40. Esto no significa, por supuesto, que Desplazamientos deba ser leída como un relato de terror. Antes bien, querríamos aquí sugerir que la novela debe leerse en esa tensión que desvía fuerzas de uno y otro campo para constituir un horizonte de referencia. Y en este sentido, así como la palabra "sombra" en el epígrafe admite una lectura contra el psicoanálisis, la advertencia sobre 
el lado bueno de la sombra, constituye una advertencia contra las simplificaciones del relato de terror. Para una lectura notable sobre el inconsciente y sus versiones en la obra de Levrero ver Diego Vecchio, "Los inconscientes categoría B", en Carolina Bartalini (ed.) Escribir Levrero. Intervenciones sobre Jorge Mario Varlotta Levrero y su literatura. Buenos Aires : Eduntref, 2016. Para la relación entre psicoanálisis y relato de terror, puede verse Nöel Carroll, "La paradoja del terror", en Filosofía del terror o paradojas del corazón. Madrid : Machadolibros, 2005, pp. 330-402.

41. Existe una estrecha relación entre los procedimientos "literarios" de los libros de Levrero y los criterios con los que Varlotta construye sus textos en revistas de juegos y suplementos culturales. Para el primer caso, véase nota 12.En 1992, en la reseña de El mayor de mis defectos, de Roberto Fontanarrosa Varlotta elogia el cuento "Elige tu propia aventura (para adultos)", que "parodia las aventuras para niños y adolescentes en las que es preciso optar en cada tramo narrativo, por continuar la aventura en una u otra de sus posibles ramificaciones. » (Mario Levrero, "El mayor de mis defectos y otros cuentos, de Roberto Fontanarrosa". Montevideo : El país cultural. Año 3, núm. 180, 7 de febrero de 1992. Pp. 10-11). Levrero (véase nota 14) no describía en términos muy diferentes la forma de Desplazamientos. Los libros para niños, los juegos parecen la matriz (vanguardista) de la que surge Desplazamientos. Agradezco a Diego Vecchio por facilitarme la reseña del libro de Fontanarrosa.

42. Diversos críticos (Hugo Verani, Oscar Steimberg, Pablo Fuentes) han señalado estos rasgos. Para un resumen de sus posiciones, ver De Rosso, op. cit..

43. Señala María Negroni : "La lírica nace y se derrocha allí [en el castillo gótico], como en esos parajes inestables donde lo único infalible es el desvío." (Negroni, María, op. cit.,21). De ser así, no podría haberse elegido otro género que el gótico para desarrollar un relato que haga del desvío su principio constructivo.

44. En las entrevistas recopiladas en Un silencio menos puede verse la recurrencia de esta apreciación. El propio antólogo, Elvio Gandolfo, la señala como una constante del libro (Elvio Gandolfo, "Prólogo". En Mario Levrero. Un silencio menos. Elvio Gandolfo (comp.). Buenos Aires : Mansalva, 2013, p. 9).

45. Eduardo Berti y Jorge Warley. "La literatura es como las palabras cruzadas". En Mario Levrero. Un silencio menos. Elvio Gandolfo (comp.). Buenos Aires : Mansalva, 2013, p. 32.

46. Mario Levrero, La novela luminosa. Buenos Aires : Mondadori, 2008, pp. 455-456.

\section{RESÚMENES}

A partir de una reflexión sobre las técnicas de escritura formulada por Mario Levrero en Irrupciones, el artículo explora la estructura de "variación modular" que caracteriza a la novela "Desplazamientos". Se argumentará aquí que el texto de Levrero debe pensarse en un doble emplazamiento que atiende, por una parte, a la historia y el desarrollo de diversas escrituras modulares en la literatura latinoamericana y, por otra, a las formulaciones que dan a ese problema escritores contemporáneos a Levrero como Saer y Arenas. El artículo explora, por último, el uso que hace la novela del horizonte temático del género de terror y el psicoanálisis junguiano. Todos estos asedios permitirían, tal nuestra hipótesis, señalar la diferencia de Levrero, su relevancia para entender las posibilidades de la literatura contemporánea.

Suscitant peu d'intérêt chez la critique et pourtant revendiqué par son auteur, le roman Desplazamientos, occupe une place singulière dans l'œuvre de Mario Levrero. En effet, il s'agit d'un 
texte central pour penser cette écriture en raison de la radicalité des procédés, moins visibles dans le reste de sa production. Dans Desplazamientos, le déploiement d'un paradigme narratif permet de penser les formes possibles du récit chez cet auteur. Notre article étudie ces paradigmes et ses relations avec certaines tendances dans la narrative latino-américaine contemporaine.

With little attention paid to it by the critics but often upheld by its author, the novel Desplazamientos occupies a singular place in Mario Levrero's output. Belonging to a little commented phase of his work in which Levrero writes other texts of "unstable description" such as Caza de Conejos and Ya que estamos, Desplazamientos stands out as an important text in the levrerian corpus because of the radical nature of the techniques he employs. In the novel, he deploys a narrative paradigm that allows the imagining of different possibilities of storytelling. This article studies this narrative strategy and its relationship with certain tendencies in contemporary Latin American narrative.

\section{ÍNDICE}

Mots-clés: littérature latino-américaine, littérature contemporaine, avant-gardes

Keywords: Latin American Narrative, contemporary Literature, avant-garde

Palabras claves: literatura latinoamericana, literatura contemporánea, vanguardias

\section{AUTOR}

EZEQUIEL DE ROSSO

UBA, UNTRE, UNA 